\title{
Injury Level of Student Male Athletes in Relation to Competitive Anxiety among M.G. University Students
}

\author{
Faazil Mohammed Khan
}

Research Scholar, School of Physical Education \& Sports Sciences, M.G University Kerala, India.

\section{ABSTRACT}

Mental elements have been fundamentally affirmed in athletic execution, sports injury avoidance, sports recovery, and as a powerful method for overseeing pressure and nervousness in rivalries. The point of this examination was to research the impact of cutthroat uneasiness on the injury level of understudy competitors of M.G University. The strategy for this examination is illustrative and correlational. The factual populace incorporates all competitors of M.G College, which are equivalent to 320 individuals. To decide the example size, Cochran's example size assessment equation was utilized and the quantity of tests was 175 , the sexual orientation irregular examining strategy chose. In the first place, to report sports wounds to portray the degree of wounds in the appendages (upper appendages, lower appendages, and trunk) and various pieces of the body (joints, muscles, and bones), the report type of sports wounds was utilized and SCAT survey was utilized to gauge cutthroat uneasiness. We investigated information utilizing SPSS programming. We utilized relapse in view of the ordinariness of the information in serious uneasiness tests and the event of sports wounds. The exploration discoveries show that the normal cutthroat uneasiness of male competitors is 14.11 and the serious tension of female competitors is 14.49. Cutthroat tension likewise has a huge constructive outcome on sports injury. The beta coefficient likewise shows that cutthroat tension predicts 0.33 changes in sports injury. Hence, it tends to be said that as the degree of cutthroat nervousness of athletic understudies increments, so does their degree of injury, and to control sports wounds, mental abilities ought to be
\end{abstract}

expanded and we should control the serious uneasiness of competitors.

Keywords: Competitive anxiety, Sports injury, Athletes

\section{INTRODUCTION}

The effect of mental elements on performing athletic abilities, anticipation of sports wounds, sports restoration, and as a successful device for overseeing pressure and nervousness in contests has been affirmed by different explores. As a rule, the reasons for wounds in competitors can be characterized into both physical and mental classifications (Armatas et al., 2007). Lately, support in aggressive games at the college level has expanded altogether. Alongside this increment, the predominance of wounds has additionally expanded contrasted with the past, so that today sports wounds and impacts are the chief purposes behind handicap in youthful competitors (Steffen et al., 2009). Accordingly, the interest for administrations given by pathology and clinical games experts is expanding. Exercise-related wounds represent a high level of all wounds announced in clinical focuses during the year (Weinberg and Gould, 2014). Exploration shows that $50 \%$ of school competitors experience the ill effects of some type of actual injury during a match season (Maddison and Prapavessis, 2007).

Sports wounds are brought about by an active work that is done to invest relaxation energy or a more particular 
reason. These wounds may likewise result from mishaps or exhaust (over the top movement) and are not quite the same as wounds from non-athletic exercises. Numerous games wounds are irrelevant and don't keep common competitors from participating in day by day exercises. Yet, for individuals who practice genuinely, every day exercises are not, at this point the lone issue. Wounds should be viably treated to empower sporting exercises at the soonest opportunity (Alizadeh et al., 2006). Sports wounds are wounds that happen because of extreme wounds or exorbitant and inordinate extending during sports developments and have a wide reach as far as type and area of the injury. Exploration shows that in many games, most we relate wounds to the lower appendages (Abernethy and Bleakley, 2007). Shojauddin et al. (2008) in an investigation of understudy competitors showed that the lower appendages with $35.7 \%$ had the most noteworthy pace of injury, and the head and face with $11.27 \%$ had the least pace of injury. This data is fundamental for clinical athletic colleagues since they are liable for the prompt consideration of competitors. Albeit the chief focal point of these people ought to be on the anticipation and treatment of actual wounds, it is critical to know about competitors' psychological states and how they identify with the setting of their wounds (Glick and Horsfall, 2001). As per different investigations, a few mental elements may assume a part in sports wounds, the most significant of which are exceptionally serious nervousness, low confidence, high pressure, way of life changes, and decreased social help. Shahbazi et al. (2011) and Bigler et al. (2014) in their exploration affirmed the impact of mental elements on sports injury. Likewise, some mental components reinforce and improve the exhibition of competitors; fortifying these variables decreases the danger of injury and velocities up the recuperation interaction of sports wounds (Johnson, 2006). A few scientists accept that nervousness in sports rivalries, tension, and mental states is identified with the quantity of wounds, and factors like brutality, antagonism, and negative mental states are viable in the seriousness of injury (Hardy, 1992). In brain research, tension is the body's normal reaction to risk. Nervousness isn't remarkable, it is upsetting when the competitor is disturbed and restless for no evident explanation, where case he loses his productivity and will be in incredible peril at the contest (Weinberg and Gould, 2014).

Nervousness is perhaps the most questionable and significant issues in brain science and influences all mental and actual components of individuals. Every one of the people have encountered tension. Some life occasions caution us we are in a perilous circumstance. Under these conditions, uneasiness is a characteristic response, in light of the fact that the work of tension is to prepare the body's guards (Gunnoe et al., 2001). Eskandari et al. (2016) inferred that there is an immediate and huge connection between the degree of sports tension (physical, psychological, and decentralization) and the aggregate sum of sports wounds that happened to competitors during contests, just as the previous year. Gunnoe et al. (2001) detailed in an examination that players with intense nervousness are bound to be harmed and the level of various wounds is higher (Gunnoe et al., 2001). Rezaei (2005) has deduced in his exploration that there is a huge connection between serious tension and the commonness of sports wounds in wrestling and handball. Notwithstanding, some examination has shown that cutthroat uneasiness doesn't influence sports injury, including Weiss (2003) and Smith et al. (1994) and Velayati et al. (2012). We can connect tension with actual issues (actual nervousness) and negatively affect individuals' reasoning and cognizance (intellectual uneasiness or stress) and can upset competitors' core interest. Following this reduction in focus, we open competitors to injury (Weinberg and Gould, 2014). Because of the way that reviews on the 
connection between cutthroat tension level and injury rate are extremely restricted and furthermore the need to lead studies to inspect harmed and healthy athletic understudies as far as uneasiness level, in this examination, the impact of serious nervousness on the injury level of understudy competitors of M.G college has been researched and its impact on the injury of competitor understudies has been contemplated.

\section{METHOD}

The technique for this examination is elucidating and correlational. The measurable populace incorporates all competitors of M.G College, which are equivalent to 320 individuals. To decide the example size, Cochran's example size assessment equation was utilized and the quantity of tests was 175, the sexual orientation arbitrary inspecting technique chose. In the initial step, we estimated the degree of serious nervousness of athletic understudies utilizing the Sports Competitive Anxiety Questionnaire (SCAT). The SCAT sports Competitive uneasiness is a test for estimating cutthroat tension in sports. The test was created in 1976 by Martinez in the United States following five years of testing on 4,000 subjects. This poll has 21 expressions for estimating 3 subscales of actual uneasiness (9 articles), psychological tension (7 articles), and decentralization (5 articles) (Wilson and Syrotuik, 2000). The legitimacy and unwavering quality of this test have been acquired, and a few examinations and scientists have announced the high legitimacy and dependability of this test. For instance, the exploration of Martens (1977,1987) estimated the legitimacy and dependability of this test and expressed that this survey has adequate principles for mental tests. In the subsequent advance, to assess sports wounds to depict the degree of wounds in the appendages (upper appendages, lower appendages and trunk) and various pieces of the body (joints, muscles, and bones), the announcing type of sports wounds is utilized, and the necessary data depends on interviews with competitors and data on the kind and seriousness of wounds were gotten by their clinical records. They gathered this structure in an examination by Rezaei (2005) and we detailed its legitimacy to be 0.78 . In this examination, we recorded wounds that happened during preparing or rivalry, during which the harmed player couldn't partake in the instructional course or the following day's match of the group. At this stage, the mentors of the groups were gotten some information about the wounds of the major parts in the injury enrollment structure (Soligard et al., 2010). Additionally, age, sex, injury status (rivalry or preparing), and sports were resolved in the primary survey and distinct measurements techniques for serious uneasiness and pervasiveness were resolved utilizing SPSS programming. Due to the ordinariness of the information in mental tests and the event of sports wounds, relapse was utilized.

\section{RESULTS}

Table 1: Demographic information
\begin{tabular}{|c|c|c|c|}
\hline Var. & Age & Height & Weight \\
\hline Mean & 23.48 & 172.52 & 68.85 \\
\hline Standard deviation & 1.13 & 3.42 & 6.74 \\
\hline
\end{tabular}

According to the results of the table above, the average age of student-athletes is 23.48 , their average height is 172.52 and the average weight of student-athletes is equal to 68.85 .

Table 2: Average and standard deviation of athletes'
competitive anxiety in terms of gender
\begin{tabular}{|c|c|c|}
\hline Gender & Mean & Standard deviation \\
\hline Male & 14.13 & 1.20 \\
\hline Female & 14.51 & 1.26 \\
\hline
\end{tabular}

According to the results of the above table, the average competitive anxiety of male athletes is 14.13 and the competitive anxiety of female athletes is 14.51 .

Table 3: Summary of regression model the effect of competitive anxiety on sports injury

\begin{tabular}{|c|c|c|}
\hline R & R Square & Adjusted R Square \\
\hline .33 & .10 & .09 \\
\hline
\end{tabular}


According to the results of Table 3, the correlation coefficient between competitive anxiety and sports injury is 0.33 and the coefficient of determination is 0.10 .
In other words, it can be said that 0.10 changes in sports injuries are determined by competitive anxiety and 0.90 are determined by other variables.

\begin{tabular}{|c|c|c|c|c|c|c|}
\hline \multirow[t]{2}{*}{ Sig. } & \multirow[t]{2}{*}{$\mathbf{t}$} & \multirow{2}{*}{$\frac{\text { Standardized Coefficients }}{\text { Beta }}$} & \multicolumn{2}{|c|}{ Unstandardized Coefficients } & \multirow{2}{*}{\multicolumn{2}{|c|}{ Model }} \\
\hline & & & Std. Error & B & & \\
\hline .000 & 7.99 & & .121 & 1.021 & (Constant) & \\
\hline .000 & 7.782 & .332 & .033 & .298 & Competitive anxiety & 1 \\
\hline
\end{tabular}

According to the results of Table 4 and considering the significant level of test error for the confidence level of 0.95 , it can be said that competitive anxiety has a significant positive effect on sports injury. The beta coefficient also shows that competitive anxiety predicts 0.33 changes in sports injury.

\section{DISCUSSION}

Research has shown that athletes who practice mental skills are less likely to be injured than other athletes. However, little research has been done on the level of competitive anxiety with the injury. Therefore, the aim of the present study was to investigate the effect of competitive anxiety on the injury level of studentathletes of M.G University. According to the results of the research, competitive anxiety has a significant positive effect on sports injury. The beta coefficient also shows that competitive anxiety predicts 0.33 changes in sports injury. In other words, with the increase in the level of sports competition among M.G university sports students, the rate of sports injuries among them will also increase. In general, research on psychological characteristics, especially in the field of sports and exercise, is controversial. Some researchers immediately linked psychological traits to athlete injury, and another group believed that it was not significant. Shahbazi et al. (2011) examined the relationship between mental skills and sports injuries in athletes present at the Student Sports Olympiad and found a significant relationship between cognitive skills and sports injuries. Bigler et al. (2014) also stated in a study that there is a significant relationship between basic mental skills, psychosomatic skills, and cognitive skills with the number of injuries of football players. Also, Ivarsson and Johnson (2010) in a study conducted with the presence of 152 male and female football players introduced psychological factors as predictors of sports injuries. Kleinert (2007) also stated that they can associate psychological and personality factors with the injury.

The results of the research are consistent with the results of Eskandari et al. (2016) research. In their study, they concluded that there was a direct and significant relationship between the level of sports anxiety (physical, cognitive, and decentralization) and the total amount of sports injuries that occurred to athletes during competitions and the past year. The results of the study are consistent with the findings of Gonavi et al. (2001). In one study, they reported that players with acute anxiety were more likely to be injured and that the percentage of various injuries was higher (Gunnoe et al., 2001). The results are also consistent with Rezaei's (2005) research findings, which show that there is a significant relationship between competitive anxiety and the prevalence of sports injuries in wrestling and handball. These results are consistent with Galambos et al. (2005) research and findings of Ford et al. (2000) research. Athletes with high levels of anxiety are more likely to be injured, they say.

However, the results of the study are not consistent with the findings of the Velayati study et al. Because in their research, they concluded that there was no significant difference between the mean score of competitive sports anxiety disorder 
of injured and uninjured elite basketball players. Therefore, it seems that competitive sports anxiety has nothing to do with sports injuries in Iran's elite basketball players. Research shows that athletes need to have the necessary mental skills to deal with stress and anxiety, and athletes with high competency in controlling competitive anxiety are less likely to be injured than other athletes. Low anxiety can be helpful sometimes to compete with athletes and motivate competition, but increasing anxiety reduces balance, reduces coordination between body parts, and ultimately reduces concentration, which can lead to injury among athletes because of Losing balance and falling, colliding with the opposing player and twisting the leg and other limbs (Johnson, 2006).A person with a high level of anxiety often behaves disproportionately in threatening situations, for example, it causes losing focus of the athlete, disrupting the regulation of a physical activity that is involved in the possibility of injury, and thus increasing the risk of injury (Nideffer, 1983).In general, it can be said that if a person's perception causes an imbalance between needs and the person's ability to respond, he or she will feel fear, resulting in increased anxiety. With this increase, anxiety (cognitive anxiety), physiological activity (physical anxiety) peaks, and is accompanied by other responses such as changes in attention and concentration, and in general, all these factors lead to the disorder in the individual and Increasing the likelihood of injury for him. Despite all the facilities and conditions, there may still be a risk of injury, and any injury may have serious psychological consequences that can cause anxiety.

\section{CONCLUSION}

In this manner, approaches to avoid injury and nervousness needs to be distinguished and we should take vital measures according to them. Given that it fundamentally related the degree of sports uneasiness in this investigation to the measure of sports wounds, we prescribe it to decrease pressure and diminish the degree of sports wounds by utilizing pressure the executive's strategies and controlling competitors' mental elements. The capacity to manage mental elements, including tension, is a killing component in decreasing the danger of injury. Because of the way that stressors may rely upon within or outside of the activity field, stress the executives components ought to be distinguished and applied. One of the essential and least complex neutralizers of stress the executives is by all accounts social help from exceptional individuals. To this end, the degree of consciousness of mentors and those associated with sports ought to be expanded to know about how to manage the competitor and to try not to make negative mental and stress factors that may prompt injury. Actual schooling educators, sports injury subject matter experts, and sports analysts are additionally encouraged to utilize mental preparing and instructive systems to attempt to improve intellectual abilities and diminish tension in athletic understudies, along these lines lessening the danger of sports wounds in them.

\section{Acknowledgement: None}

\section{Conflict of Interest: None}

\section{Source of Funding: None}

\section{REFERENCES}

1. Abernethy, L., \& Bleakley, C. (2007). Strategies to prevent injury in adolescent sport: A systematic review. $\mathrm{Br} J$ Sports Med, 41, 627-38. https://doi.org/10.1136/ bjsm.2007.035691

2. Alizad, M. H., Qara Khanlou, R., \& Daneshmandi, H. (2006). Prevention and treatment of sports injuries. Organization for the Study and Compilation of Textbooks (Samt) (pp. 1-10).

3. Armatas, V., Chondrou, E., Yiannakos, A, Galazoulas, Ch., \& Velkopoulos, C. (2007). Psychological aspects of rehabilitation following serious athletic injuries with special reference to goal setting: A review study. Physical Training, June (1). Retrieved July 12, 2007, from 
Faazil Mohammed Khan. Injury level of student male athletes in relation to competitive anxiety among M.G University students

http://ejmas.com/pt/2007pt/ptartgalazoulas0 707html

4. Bigler, K., Alizadeh, M. H., \& Khabiri, M. (2014). Investigating the Relationship between Psychological Skills and Injuries of Football Players of Tehrani Teams of Iran Premier League. Journal of Sports Medicine (Movement), 6(2), 89-102.

5. Eskandari, I., Ghaderian, M., \& Zolaaktaf, V. (2016). The relationship between the level of sports anxiety and the incidence of sports injuries in wrestling students. Journal of Sports Psychology, 5(13), 39-48.
6. Ford, I. W., Eklund, R. C., \& Gordon, S. (2000). An examination of psychosocial variables moderating the relationship between life stress and injury time-loss among athletes of a high standard. Journal of Sports Sciences, 18(5), 301-12. https://doi.org/10.1080/026404100

How to cite this article: Khan FM. Injury level of student male athletes in relation to competitive anxiety among M.G University students. International Journal of Science \& Healthcare Research. 2021; 6(2): 202-207. DOI: https://doi.org/10.52403/ijshr.20210437 